\title{
Diagnóstico da implementação de resíduos de construção e demolição na Cidade de Campina Grande - PB
}

Diagnosis of the implementation of construction and demolition waste in the City of Campina Grande - PB

Diagnóstico de la aplicación de residuos de construcción y demolición en la Ciudad de Campina Grande - PB

Recebido: 22/05/2020 | Revisado: 24/05/2020 | Aceito: 29/05/2020 | Publicado: 15/06/2020

Osires de Medeiros Melo Neto

ORCID: https://orcid.org/0000-0002-2535-0969 Universidade Federal de Campina Grande, Brasil E-mail: osiresdemedeiros@gmail.com Gustavo Correia Basto da Silva ORCID: https://orcid.org/0000-0002-6081-2540 Universidade Estadual da Paraíba, Brasil E-mail: gugacorreiaa@gmail.com

\section{Resumo}

A principal categoria de resíduos sólidos é a dos resíduos de construção e demolição, importante devido ao alto volume e produção em massa. Neste estudo, objetiva-se desenvolver um panorama acerca da viabilidade da implementação do RCD na construção civil na Cidade de Campina Grande - PB. Fez-se uma pesquisa através de um questionário com estudantes do curso de engenharia civil e uma empresa do ramo da construção civil, analisando seus conhecimentos a respeito da produção de RCD na cidade, reciclagem dos resíduos e implementação de medidas sustentáveis nesse âmbito. Os resultados do questionário confirmam a difusão do tema entre os alunos, porém demonstra necessidade da abordagem de empresas que empregam RCD nas suas práticas construtivas. A empresa avaliada afirma consciência sobre o tema e declara que as empresas do ramo são orientadas ao reaproveitamento desses resíduos. Portanto, é necessário dissertar sobre empresas sustentáveis 
durante aulas e seminários nas universidades a fim de estimular os futuros empreendedores do ramo da construção civil a implementarem medidas sustentáveis.

Palavras-chave: Engenharia Civil; RCD; Sustentabilidade.

\begin{abstract}
The main category of solid waste is construction and demolition waste, important due to the high volume and mass production. In this study, the objective is to develop an overview of the feasibility of implementing RCD in civil construction in the city of Campina Grande - PB. A survey was carried out through a questionnaire with students from the civil engineering course and a company in the civil construction sector, analyzing their knowledge regarding the production of RCD in the city, recycling of waste and the implementation of sustainable measures in this area. The results of the questionnaire confirm the diffusion of the theme among the students, but it demonstrates the need to approach companies that use RCD in their constructive practices. The evaluated company affirms its conscience on the subject and declares that the companies in the sector are oriented to the reuse of this waste. Therefore, it is necessary to talk about sustainable companies during classes and seminars at universities in order to encourage future entrepreneurs in the construction industry to implement sustainable measures.
\end{abstract}

Keywords: Civil Engineering; RCD; Sustainability.

\title{
Resumen
}

La principal categoría de residuos sólidos es la de residuos de construcción y demolición, importante debido al alto volumen y la producción en masa. En este estudio, el objetivo es desarrollar una visión general de la viabilidad de implementar RCD en la construcción civil en la ciudad de Campina Grande - PB. Se realizó una encuesta a través de un cuestionario con estudiantes del curso de ingeniería civil y una empresa del sector de la construcción civil, analizando sus conocimientos sobre la producción de RCD en la ciudad, el reciclaje de residuos y la implementación de medidas sostenibles en esta área. Los resultados del cuestionario confirman la difusión del tema entre los estudiantes, pero demuestra la necesidad de acercarse a las empresas que usan RCD en sus prácticas constructivas. La empresa evaluada afirma su conciencia sobre el tema y declara que las empresas del sector están orientadas a la reutilización de estos residuos. Por lo tanto, es necesario hablar sobre empresas 
sostenibles durante las clases y seminarios en las universidades para alentar a los futuros empresarios de la industria de la construcción a implementar medidas sostenibles.

Palabras clave: Ingeniería Civil; RCD; Sustentabilidad.

\section{Introdução}

O desdém das consequências mais amplas do desenvolvimento econômico acarretou a uma crise ambiental global movida parcialmente por recursos materiais desperdiçados e pelo ritmo acelerado da geração de resíduos de construção e demolição (RCD) (Saéz; Osmani, 2019).

A composição do RCD varia de acordo com o tipo de obra que está sendo executada, encontrando em sua constituição materiais como concreto, asfalto, gesso, metais, britas, vidros, plásticos, solos e rochas de limpezas de terrenos e escavações, madeiras e compensados, forros, tijolos, blocos cerâmicos, componentes como portas, janelas, tubulações, e até mesmo materiais perigosos como resinas, colas, tintas, asbestos e metais pesados.

A procura pela sustentabilidade, que refere-se à interação entre o ser humano e o mundo cuidando do meio ambiente e preservando os recursos naturais, deve ser constante em todas as esferas sociais, econômicas e políticas (Melo Neto; Silva, 2020).

O interesse no tema meio ambiente implica, pelas atividades na aplicação sustentável da biodiversidade, a geração de conhecimento por meio de trabalhos na área empresarial e apoio de populações locais, especialmente no Brasil. O desenvolvimento sustentável tem competência de intervir direta e indiretamente na conduta das empresas, dado que, em todos os países, as empresas estão embatendo com problemas não apenas financeiros, mas sociais e ambientais (Melo; Melo Neto; Silva; Sousa, 2020).

Melo Neto, Silva e Melo (2020) realizaram um estudo através de questionários na cidade de Campina Grande - PB com alunos da Universidade Federal de Campina Grande e habitantes das redondezas do campus a fim de apresentar um diagnóstico sobre a implementação de um semáforo próximo à rotatória que viabiliza a segurança e otimização do fluxo de veículos. Tendo em vista a pesquisa acima citada, constatou-se a eficácia na implementação de questionários online no município, estimulando a realização dessa pesquisa num contexto ambiental tão narrado pelo mundo. 
Assim, o presente estudo tem como objetivo desenvolver um panorama acerca da viabilidade da implementação do RCD na construção civil na cidade de Campina Grande PB.

\section{Metodologia}

Realizou-se uma pesquisa através de um questionário com estudantes do curso de engenharia civil da Universidade Federal de Campina Grande e com a empresa Cipresa Empreendimentos LTDA do ramo da construção civil, localizada no bairro Catolé na cidade de Campina Grande - PB. Avaliou-se conhecimentos a respeito da produção de RCD na cidade, reciclagem dos resíduos e implementação de medidas sustentáveis nesse âmbito.

No estudo foi desenvolvido um questionário com acesso disponível através de uma página da internet realizado pelo Google Docs, composto por 05 (cinco) questões e de acesso livre para todas as pessoas que tivessem acesso ao link. O link foi disponibilizado apenas para alunos do curso de engenharia civil da Universidade Federal de Campina Grande e as questões foram de múltiplas escolhas, onde o entrevistado estava sujeito a responder: sim, não ou não sabe responder. A Tabela 1 apresenta o questionário utilizado com os alunos.

Tabela 1. Questionário aplicado aos alunos de engenharia civil.

\section{PERGUNTAS}

Primeiramente, você já ouviu falar em Resíduos de Construção e Demolição, conhecido pela sigla $\mathrm{RCD}$ ?

Durante sua graduação, alguma disciplina explanou sobre uso de RCD no ramo da construção civil?

Você conhece algum tipo de material de construção civil que após ser descartado, passe a ser reutilizado no ramo da construção civil?

Você tem conhecimento de alguma empresa ou construtora que faça uso do RCD para reutilização na construção civil?

Após sua formação e caso tenha conhecimento sobre a reutilização e importância do RCD, você pretende utilizar esse tipo de material em seu campo de trabalho?

Fonte: Adaptado de Melo Neto, Silva e Melo (2020). 
Research, Society and Development, v. 9, n. 7, e802974826, 2020

(CC BY 4.0) | ISSN 2525-3409 | DOI: http://dx.doi.org/10.33448/rsd-v9i7.4826

A entrevista com a empresa Cipresa Empreendimentos LTDA foi de cunho informativo, a qual abordou a relevância e a atual situação do desperdício de resíduos de construção e demolição no município de Campina Grande - PB, sendo possível observar o entendimento, aceitação e uso de RCD no campo de trabalho. A Tabela 2 apresenta o questionário realizado com a empresa.

Tabela 2. Questionário aplicado a empresa avaliada.

\section{PERGUNTAS}

Você tem conhecimento do que é RCD?

A empresa utiliza ou já utilizou RCD como material de construção?

A empresa possui projeções a respeito do uso do RCD?

Qual a importância, em sua opinião, do uso do RCD?

Fonte: Adaptado de Melo Neto, Silva e Melo (2020).

\section{Resultados e Discussão}

Obteve-se 306 respostas ao questionário online sobre a implementação de medidas sustentáveis no âmbito da construção civil. Das quais se podem avaliar o conhecimento dos estudantes acerca dos RCD. A Tabela 3 apresenta os resultados para cada pergunta realizada. 
Tabela 3. Resultados obtidos com o questionário realizado para os alunos de engenharia civil.

\begin{tabular}{lccc}
\hline \multicolumn{1}{c}{ PERGUNTAS } & Sim & Não & $\begin{array}{c}\text { Não Sabe } \\
\text { Responder }\end{array}$ \\
\hline $\begin{array}{l}\text { Primeiramente, você já ouviu falar em Resíduos de Construção e } \\
\text { Demolição, conhecido pela sigla RCD? }\end{array}$ & 270 & 12 \\
\hline $\begin{array}{l}\text { Durante sua graduação, alguma disciplina explanou sobre uso de } \\
\text { RCD no ramo da construção civil? }\end{array}$ & 195 & 86 & 25 \\
\hline $\begin{array}{l}\text { Você conhece algum tipo de material de construção civil que após } \\
\text { ser descartado, passe a ser reutilizado no ramo da construção civil? }\end{array}$ & 269 & 37 & 0 \\
\hline $\begin{array}{l}\text { Você tem conhecimento de alguma empresa ou construtora que } \\
\text { faça uso do RCD para reutilização na construção civil? }\end{array}$ & 25 & 244 & 37 \\
\hline $\begin{array}{l}\text { Após sua formação e caso tenha conhecimento sobre a reutilização } \\
\text { e importância do RCD, você pretende utilizar esse tipo de material } \\
\text { em seu campo de trabalho? }\end{array}$ & 244 & 25 & 37 \\
\hline \multicolumn{1}{c}{ TOTAL DE ALUNOS ENTREVISTADOS } & $\mathbf{3 0 6}$ & \\
\hline
\end{tabular}

Fonte: Adaptado de Melo Neto, Silva e Melo (2020).

Dos alunos que responderam o questionário $88 \%$ afirmaram que já ouviram falar em RCD, $8 \%$ não ouviram falar e $4 \%$ não souberam responder. Cerca de $64 \%$ dos entrevistados já ouviram falar no tema dentro da universidade através de disciplinas, $28 \%$ não tiveram essa oportunidade e apenas $8 \%$ não souberam responder.

O conhecimento a respeito de materiais da construção civil que mesmo após tornaremse resíduos possuem características significativas em seu reuso foi de $88 \%$ entre os alunos, sendo $12 \%$ desconhecidos do assunto. A pergunta que obteve maior percentagem negativa foi acerca de informações sobre empresas sustentáveis com $80 \%$ respondendo não tendo essa compreensão, $8 \%$ afirmando que sim e $12 \%$ não souberam responder. O último questionamento foi sobre aderir a implementação de RCD após formação acadêmica e inserção no mercado de trabalho, obtendo-se $80 \%$ dos internautas respondendo sim, $8 \%$ optando por não e $12 \%$ não souberam responder.

As respostas do questionário que estavam classificadas como Não Sabe Responder foram excluídas a fim de direcionar a pesquisa para respostas positivas (sim) e negativas (não). Considerou-se o questionário como um todo após analisar individualmente cada 
questão abordada. A Figura 1 apresenta os resultados do questionário como positivos e negativos.

Figura 1. Resultado das respostas do questionário.

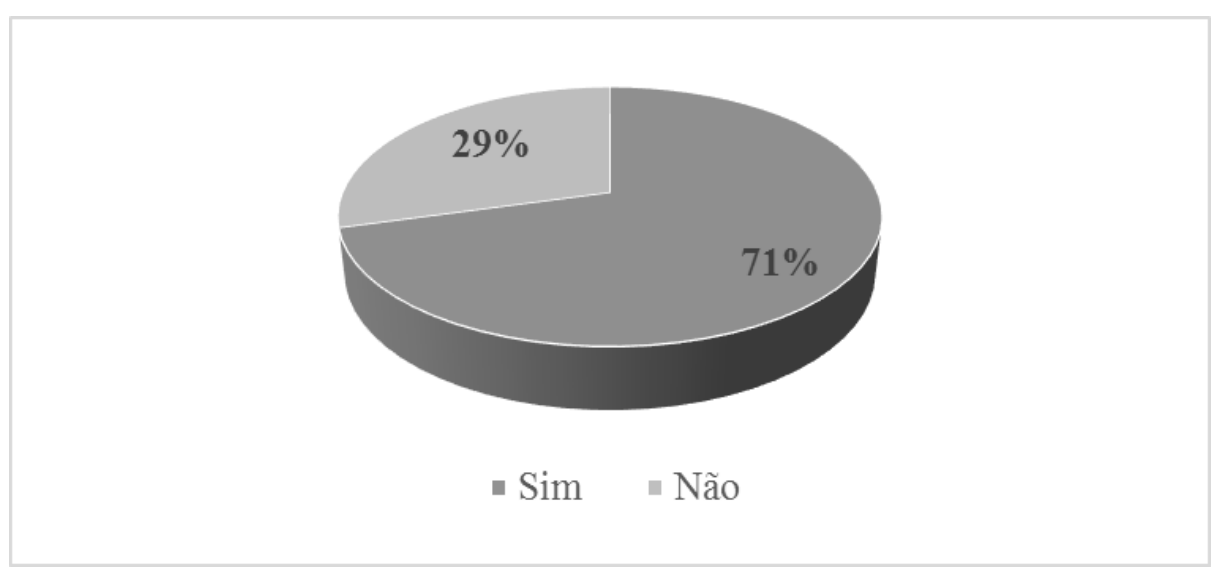

Fonte: Autores (2020).

De acordo com a Figura 1, observa-se que aproximadamente $70 \%$ dos entrevistados apresentam conhecimentos acerca dos RCDs e que apoiam a sua implementação na construção civil. Contudo, existe ainda uma porcentagem de alunos que são desinformados a respeito desse tema.

O questionário realizado com a empresa Cipresa Empreendimentos LTDA permitiu perceber que a empresa apresenta conhecimento acerca dos RCDs. Afirma-se ao ser questionada sobre a utilização dos resíduos como material de construção, que a maioria das empresas da construção civil são certificadas com a ISO 9001 e, orientadas a reaproveitar os resíduos de construção da forma mais eficiente possível. Portanto, a empresa já adota medidas sustentáveis, como exemplo a transformação de alguns resíduos em areia que é utilizada na construção.

Quando questionada sobre possíveis projeções a respeito do uso do RCD, a empresa respondeu que tem total empenho sobre utilização futura, justificando que ao diminuir o índice de desperdício na construção, também diminuirá custos e, consequentemente, ocorrerá ganhos tanto ambientais como econômicos.

Finalizou-se questionando a empresa sobre a importância do uso do RCD, obtendo-se como resposta a necessidade e o cuidado com o meio ambiente que a empresa deve ter, 
priorizando a reutilização dos materiais que seriam previamente descartados a fim de minimizar os custos.

\section{Considerações Finais}

A pesquisa com os alunos de engenharia civil foi satisfatória, pois pode-se ter uma ampla visão da realidade dos futuros profissionais desse ramo. Conclui-se que alunos de engenharia têm certo conhecimento sobre a área de RCD dentro da própria instituição de graduação e com isso já podem aflorar seus pensamentos para a área sustentável, buscando minimizar os impactos causados pelo entulho.

A maximização da abordagem de empresas que empregam RCD em suas práticas construtivas é de fundamental importância a fim de estimular os futuros empreendedores do ramo da construção civil a implementarem medidas sustentáveis.

A empresa avaliada apresentou-se bem informada quanto ao tema exposto e, também, disponível para implementação de medidas sustentáveis com RCD em suas construções. Contudo, a empresa já aplica pequenas ações sustentáveis em seus métodos construtivos, favorecendo a sustentabilidade ambiental.

\section{Referências}

Ansari, M.; \& Ehrampoush, M. H. (2018). Quantitative and qualitative analysis of construction and demolition waste in Yazd city, Iran. Data in Brief, 21, 2622-2626.

Ghaffar, S. H.; Burman, M.; \& Braimah, N. (2020). Pathways to circular construction: An integrated management of construction and demolition waste for resource recovery. Journal of Cleaner Production, 244, 1-9.

Martins, A. S. M.; Reis, D. C.; \& Fabricio, M. M. (2019). Diretrizes para o planejamento de uma demolição seletiva em edifícios. Interações, 20(2), 487-507. 
Melo, T. G. P. R.; Melo Neto, O. M.; Silva, G. C. B.; \& Sousa, M. S. (2020). Empresas

Rurais: importância da preservação ambiental frente ao desenvolvimento econômico. Research, Society and Development, 9(4), 1-23.

Melo Neto, O M.; Silva, G. C. B.; \& Melo, T. G. P. R. M. (2020). Melhoria no fluxo de veículos e segurança de pedestres: estudo com usuários na viabilização de semáforos próximos à rotatória. Research, Society and Development, 9(4), 1-15.

Melo Neto, O. M.; \& Silva, G. C. B. (2020). Meio Ambiente: Construções Civis e a Saúde Pública. São Paulo: Novas Edições Acadêmicas.

Saéz, P. V.; \& Osmani, M. (2019). A diagnosis of construction and demolition waste generation and recovery practice in the European Union. Journal of Cleaner Production, 241, $1-11$.

\section{Porcentagem de contribuição de cada autor no manuscrito}

Osires de Medeiros Melo Neto - 70\%

Gustavo Correia Basto da Silva - 30\% 